\title{
The TP63 Gene Polymorphism rs17506395 is Associated with Early Breast Cancer in Cameroon
}

\author{
Arnol T Z Tiofack ${ }^{1}$, Gustave Simo ${ }^{1 *}$, Elvis A Ofon ${ }^{1}$, Ester Dina bell ${ }^{2}$, Chancelin \\ M Kamla ${ }^{3}$, Sidonie N Ananga ${ }^{4}$, Tchamfong Roger ${ }^{5}$, Theophile N Nana ${ }^{6}$, Charlotte \\ T Nguefack ${ }^{6}$, Adamou Fewou ${ }^{4,7}$, Samuel Takongmo ${ }^{7,8}$, Smiths Lueong, ${ }^{1,9 *}$
}

\begin{abstract}
Background: Breast cancer (BC) is a leading female cancer worldwide and cause of cancer-related death, especially in developing countries. Genetic predispositions to BC development in African population is poorly studied, and meanwhile the SNP rs17506395 in TP63 gene locus has been associated with the development of breast cancer in Asian women, no investigation has been undertaken within African population. We investigated the impact of this polymorphism in a representative African population. Methods: We undertook a case-control study including 335 women, of which 111 were breast cancer patients and 224 controls. Using blood-derived germline DNA, PCR-RFLP was used to investigate the polymorphism of TP63 gene at rs 17506395 locus. Unconditional logistic regression was used to study the association between the TP63 gene polymorphism and risk of BC development. After stratification into different age and ethno-linguistic groups as well as menopausal status, the Cochran-Mantel-Haenszel test was used to measure significance of the associations. Results: Comparing cases with controls, no significant associations between genotype and disease development was observed. Similarly, when cases were stratified according to menopausal status and ethno-linguistic groups, no significant association was observed between genotype and disease development. However, in women of 40 years and below, TT and TG genotypes were associated with breast cancer development. The minor $\mathrm{G}$ allele seems to protective against early breast cancer onset $\mathrm{OR}$ of $0.5(95 \% \mathrm{CI}=0.26-0.94, \mathrm{p}=0.03)$. Conclusion: Our data revealed an association between rs15706395 and the risk of early breast cancer onset. The GG genotype seems to reduce the risk of early breast cancer. Larger studies are needed to confirm the potential of this SNP as biomarker for breast cancer prognostic.
\end{abstract}

Keywords: Breast cancer- early onset- TP63- single nucleotide polymorphism- rs 17506395- female- Cameroon

Asian Pac J Cancer Prev, 21 (8), 2199-2208

\section{Introduction}

Breast cancer $(\mathrm{BC})$ is one of the most common invasive malignancies among women worldwide and is the leading cause of cancer-related-deaths among women (Bray et al., 2018). It constitutes about $25 \%$ of cancers diagnosed in women (Bray et al., 2018; Ferlay et al., 2015), and its annual incidence has increased from approximately 1.67 million in 2012 to 2.1 million new cases in 2018 (Bray et al., 2018; Ferlay et al., 2015). In 2012, nearly $60 \%$ of BC-related deaths were reported in low-income countries (Ferlay et al., 2015). According to the International Agency for Cancer Research (IARC), breast cancer incidence range from 28 per 100,000 women in central
Africa to more than 37 per 100,000 women in Western Africa (Bray et al., 2018). Although BC is relatively less prevalent in Sub-Saharan Africa (SSA), survival is also generally poor in this region with high mortality recorded in many settings (Bray et al., 2018; Jedy-Agba et al., 2017).

Currently, African women under the age of 40 years with poor prognostic features are increasingly being diagnosed than older women in sub-Saharan Africa (Dia et al., 2017; Vanderpuye et al., 2017). The age at first diagnosis lies between 20 and 50 years in sub-Saharan Africa (Atangana et al., 2017; Kemfang et al., 2015; Essiben et al., 2016; Sando et al., 2014; Yomi et al., 2011; Ouedraogo et al., 2018) compared with 60 to 70 years in

\footnotetext{
${ }^{1}$ Molecular Parasitology \& Entomology Unit, Department of Biochemistry, Faculty of Science, University of Dschang, Dschang, Cameroun. ${ }^{2}$ Medical Oncology, Direction of the Bonassama District Hospital, Douala, Cameroon. ${ }^{3}$ Faculty of Medicine and Pharmaceutical Science, University of Douala, Douala, Cameroon. ${ }^{4}$ Service of AnatomocytoPathotogy, General Hospital of Douala, Douala, Cameroon. ${ }^{5}$ St. Joseph Clinic Cancer Center, Yaounde, Cameroon. ${ }^{6}$ Service of Obstetrics and Gynecology, General Hospital of Douala and Faculty of Medicine, University of Buea. ${ }^{7}$ Faculty of Medicine and Biomedical Sciences, University of Yaounde, Yaounde, Cameroon. ${ }^{8}$ Medico-surgical center of Yaounde-Nsimeyong Hospital, Yaounde, Cameroon. ${ }^{9}$ German Cancer Research Center, Essen, Germany.*For Correspondence: gsimoca@yahoo.fr, s.lueong@Dkfz-Heidelberg.de
} 
most western societies (Abdulrahman and Rahman, 2012; Ferlay et al., 2013; Karim et al., 2015). In Sub-Saharan Africa, most patients die within one year from diagnosis as a result of disease complications and aggressiveness (Jedy-Agba et al., 2016; Ly et al., 2012). Although the clinic-pathological underpinnings of disease outcomes is still poorly understood, several factors including the poor health infrastructures, the lack of screening programs in some African countries, the late diagnosis, lack of patient support programs and poor clinical among others, may explain the differences observed in breast cancer outcomes in various populations (Jill et al., 2013).

Current evidence suggests that early BC onset in patients below 40 years is clinically and etiologically distinct from breast cancer in older women (Anders et al., 2009; Bleyer et al., 2008; Karihtala et al., 2010). For instance, early onset of $\mathrm{BC}$ has specific characteristics such as worse prognosis, high aggressiveness, the higher proportions of high-grade and later-stage tumors, and lower expression of hormone receptor genes (Bleyer et al., 2008; Gnerlich et al., 2009; Jill et al., 2013). Additionally, the "triple-negative" phenotype (ER-, PR-, HER2-) of breast cancer, which seems to be more prevalent in young indigenous African and African-American women is very aggressive, lethal and recurrent (Anders et al., 2009; Eng et al., 2014; Galukande et al., 2014, Sawe et al., 2016). Although the role of accumulated driver and passenger mutations is undisputable, the importance of germline genetic variants in the development of BC is becoming an area of great interest (Mavaddat et al., 2010). Identification of genotypes associated with early disease onset holds the promise of well-tailored surveillance schemes.

Genetic variants in the TP63 gene locus has been reported to be associated with $\mathrm{BC}$ development in Asian populations (Feng et al., 2011; Guan et al., 2012; Zhang et al., 2014). The TP63 gene is located on chromosome $3 q 27$ and encode for the protein p63 that plays a crucial role in the maintenance of a stem cell population of several epithelial tissues. Although p63 is necessary for the normal development of epithelial organs including mammary glands (Barbareschi et al., 2001), its tissue expression patterns have been shown to be associated with syncytial growth pattern in triple negative breast cancer (Thike et al., 2010). Moreover, a positive association has been reported between the percentages of p63-positive cells with a marked nuclear pleomorphism (Thike et al., 2010). At the genetic level, a functional SNP rs 17506395 ( $>$ G) located in the TP63 gene, which was initially associated with fertility (Feng et al., 2011) has recently been associated with several cancers including breast cancer in Asian populations (Feng et al., 2011; Guan et al., 2012; Zhang et al., 2014). The TT genotype is associated with poor survival, suggesting that this genotype could be a biomarker of adverse prognosis in breast cancer (Zhang et al., 2014). Despite the aforementioned associations between p63 expression and/or TP63 gene polymorphism with $\mathrm{BC}$ development and patient outcome, very little, if all any study has addressed this crucial factors on $\mathrm{BC}$ development or patient outcome in African women. With this in mind, and mindful of the socio-economic and clinical impacts of $\mathrm{BC}$ in developing countries, this study was designed to understand the impact of TP63 gene polymorphism on the incidence and/or development of BC within an African context.

\section{Materials and Methods}

\section{Ethical approval and consent to participate}

This study was approved by the Ethics Review and Consultancy Committee (ERCC) of the Cameroon Bioethics Initiative (CAMBIN) under the reference number CBI/395/ERCC/CAMBIN and Protocol number 1086. All participants voluntarily signed written informed consent forms prior to their inclusion into the study and the analysis of participant data was fully anonymized.

\section{Study population}

The Cameroonian population is made up of more than 250 ethno-linguistic subgroups from three major ethno-linguistic groups: Bantu (e.g.: Bulu, Bassa, Bakundu, Maka, Douala), Semi Bantu (e.g.: Bamileke, Gbaya, Bamoun, Tikar) and Sudano-Sao (e.g.: Fulbe, Mafa, Toupouri, ShoaArabs, Moundang, Massa, Mousgoum) (Ofon et al., 2017). These different ethno-linguistic groups are spread over several African countries and thus provide an excellent opportunity of studying some global aspects of human genetics research in sub-Saharan Africa (Wonkam et al., 2011).

For this study, a total of 335 women including 111 patients and 224 controls were prospectively recruited between October 2015 and December 2016 at the oncology and radiotherapy unit of the Douala General Hospital and the St. Joseph clinic cancer center of Yaoundé. All patients were histologically confirmed with invasive breast cancer, but without other clinically detectable neoplasm (case group). Controls were randomly recruited women who had no form of cancer as determined from their medical histories and general physical examination. Women who were below 21 years old and/or not Cameroonian and/or had another type of cancer and/or refused to participate in the study were excluded. Participant information was recorded by means of a structured questionnaire that was provided to the participants after consent was given. Clinical and pathological data for all cases was obtained from the physician and/or collected from hospital records.

\section{Blood sampling and DNA Extraction}

About $5 \mathrm{ml}$ of blood sample was taken by vein-puncture into EDTA coated tubes. After centrifugation of each tube at $3000 \mathrm{xg}$ for 5 minutes, the buffy coat was collected. From each buffy coat, DNA was extracted using phenol-chloroform-isoamylic alcohol (25:24:1) and then, precipitated with isopropanol. DNA pellets were re-suspended in $50 \mu \mathrm{l}$ of sterile ultrapure water and stored at $-20^{\circ} \mathrm{C}$ until use.

\section{Genotyping of TP63 gene at rs 17506395}

Genotyping was carried out by the Polymerase Chain Reaction-Restriction Fragment Length Polymorphism (PCR-RFLP) where the TP63 gene was amplified and thereafter, the PCR products were digested with restriction enzyme before their resolution on a $2 \%$ agarose gel. 
Amplification of TP63 gene

For the amplification of TP63 gene, the primer pair Rb395F (5-ACAGATAAATTGGTGGAGAGAGAT-3) and Rb395R (5-CACTGTTTGGACCCTGGAA-3) flanking the region containing the SNP rs17506395 were designed using Primer-BLAST Software (Ye et al., 2012). The PCR reactions were carried out in a DNA thermal cycler (Prime, United Kingdom). Each amplification reaction was performed in total volume of $25 \mu \mathrm{L}$ containing 1X PCR buffer (Tris· Cl, $\mathrm{KCl}$, (NH4)2SO4, 1.5 mM MgCl2), 1X Q-Solution (Cat No/ID: 203203 Qiagen, Germany), $20 \mathrm{pmol} / \mathrm{L}$ of each primers, $200 \mathrm{nmol} / \mathrm{L}$ of each dNTP, $1.5 \mathrm{mM} \mathrm{MgCl2}, 0.25 \mathrm{U}$ Hot star Taq DNA polymerase (Qiagen), and $5 \mu \mathrm{L}$ of genomic DNA diluted 10 fold. The amplification reactions included a denaturation step at $95^{\circ} \mathrm{C}$ for $15 \mathrm{~min}$ followed by 40 amplification cycles comprising a denaturation step at $95^{\circ} \mathrm{C}$ for $30 \mathrm{~s}$, an annealing step at $58^{\circ} \mathrm{C}$ for $45 \mathrm{~s}$ and an extension step at $72^{\circ} \mathrm{C}$ for $1 \mathrm{~min}$. This was followed by a final extension step at $72^{\circ} \mathrm{C}$ for $10 \mathrm{~min}$. For every PCR reaction, a negative control was included where the nuclease free water was used instead of the DNA. The amplified products were resolved by electrophoresis at 135 volts for $30 \mathrm{~min}$ on $2 \%$ agarose gel containing ethidium bromide. The gels were visualized under ultraviolet light and then photographed using a gel documentation system (UVIsave HD5, Unitec Cambridge). Samples with a successful amplification of the target region (450bp fragment) were selected and subjected to digestion with restriction enzyme.

\section{Digestion of PCR products}

For this digestion, $10 \mu \mathrm{L}$ of PCR product were mixed with 10 units $(1 \mu \mathrm{L})$ of MboII restriction enzyme (Cat \#: R0148L; Lot number: 0911511, New England Biolabs, Inc.). The digestion was performed for 18 hours at $37^{\circ} \mathrm{C}$. The digested products were subsequently resolved on a $2 \%$ agarose gel containing ethidium bromide. Samples presenting two DNA fragments of 235 and $215 \mathrm{bp}$ were considered as homozygote wild type with genotype TT while those showing a single DNA fragment of $450 \mathrm{bp}$ were considered as homozygous mutant with genotype GG. A profile showing three DNA fragments of 235 , 215 , and $450 \mathrm{bp}$ were considered as heterozygote with genotype TG.

\section{Power calculation}

For this study, we assumed an additive genetic model where two risk alleles of an SNP (homozygous) have twice the effect of one risk allele (heterozygous) (Menashe et al., 2008). Power calculations were undertaken using the PGA modeller package in MATLAB (Menashe et al., 2008). For this Software, the power was calculated by considering an odd ratio (OR) or relative risk $(\mathrm{RR}) \geq 2$ for locus with disease allele frequency of $0.1612-0.205$ with one locus genotyped. Other factors taken into consideration include the disease prevalence estimated at $25 \%$ according to GlOBOCAN 2012 (Ferlay et al., 2015), a type 1 error of $5 \%$ risk, a complete linkage parameter $\left(\mathrm{r}^{2}\right)$ for linkage disequilibrium (LD) of 1.0 and the sampling size. This later was estimated as described by Kasiulevicius et al., (2006) using the independent case-control sampling size formula. For this estimation, we assumed an expected exposure proportions in control of $20 \%$, a disease prevalence of $25 \%$ (Ferlay et al., 2015) and a case-control ratio of 1:2. With the independent case-control sampling size formula, the sampling size to detect a real odds ratio or case exposure rate with power and two-sided type I error of 5\% risk was 195 including 65 breast cancer patients and 130 controls.

\section{Association studies}

Before the association studies, the Hardy-Weinberg equilibrium test (HWE) was undertaken not only on the entire population, but also on different subpopulations stratified by ages, menopausal status and ethno-linguistic subgroups.

To test if there was any association between polymorphism at SNP rs 17506395 of TP63 gene and the risk of breast cancer development, the association analysis were firstly performed on the entire population made up of 111 patients and 224 controls. For these association studies, the unconditional logistic regression models were used to estimate odds ratio (OR) at $95 \%$ confidence intervals $(\mathrm{CI})$ in the entire population without any stratification as well as in each stratified population. When the absence of one genotype or allele (represented by zero) has led to problems with the computation of the odds ratio (standard error), 0.5 was added to all cells (values involved in formula) as supposed by Deeks and Higgins (2010) (Pagano and Gauvreau, 2000; Deeks and Higgins, 2010). Pearson chi-square $\left(\chi^{2}\right)$ tests and the Fisher's exact test were used to compare categorical variables between the participants while the student t-test was used to compare the mean values for continuous variables between groups. The test was considered significant for a $\mathrm{P}$ value below 0.05 .

To see if the heterogeneous nature of our study population, made up of women having different menopausal status or belonging to different age groups or various ethno-linguistic subgroups, could have an effect on the results of association studies, additional analyses were undertaken on different subpopulations. Each subpopulation was considered here as all women belonging to the same ethno-linguistic group or the same age group or having the same menopausal status. These analyses were performed when the participants were subdivided according to their menopausal status, their ethno-linguistic groups (Bantu, semi-Bantu and Sudano-sao) and their age group (women $\leq 40$ years old and those above 40). For these stratified population, the Cochran-Mantel-Haenszel (CMH) test implemented in PLINKv1.9 package (Purcell et al., 2007) was performed with the allelic frequencies because this test can only be done with binary vars. The $\mathrm{CMH}$ test enabled not only to estimate the odds ratio and $95 \%$ confidence interval across the stratified population, but also to test the associations between alleles and the probability to develop a breast cancer in each stratum. Moreover, the CMH2 test, also implemented in PLINKv1.9 package, was used to determine if there were significant differences between the allele frequencies of different subpopulations. The genotype-based Cochran-Armitage trend test with 
high power and two degrees of freedom (in the $2 \times 3$ crosstab) was performed to test the association between rs 17506395 and the susceptibility to breast cancer. The statistical analyses were conducted using SPSS Software 22.0 (SPSS Inc., Chicago, Illinois, USA) and PLINK v1.9 package. The chi-squared test was used to compare the allelic and genotypic frequencies between breast cancer patients and controls.

\section{Results}

Socio-demographic and clinical characteristics of the study population

In our study, 335 Cameroonian women were recruited: 111 breast cancer patients who were histologically confirmed with infiltrating ductal carcinomas and 224 controls (Table 1). Amongst the 335 participants, 74 (22.09\%) were Bantu, 254 (75.82\%) semi Bantu and 7 (2.09\%) Sudano-Sao. The age of breast cancer patients at diagnosis ranged from 24 to 72 years with a mean of 41.64 $(\mathrm{SD}=12.31)$ years while those of the controls were range from 25 to 78 years with a mean of $39.55(\mathrm{SD}=10.63)$ years. No significant difference was observed between mean age of patients and controls $(p$-value $=0.11)$.

Table 1. Socio-Demographic and Clinical Characteristics of the Study Population

\begin{tabular}{|c|c|c|c|}
\hline Clinical & $\begin{array}{c}\text { Cases, } \\
\mathrm{n}=111(\%)\end{array}$ & $\begin{array}{l}\text { Controls, } \\
\mathrm{n}=224(\%)\end{array}$ & $P$-value \\
\hline \multicolumn{3}{|l|}{ Age group } & 0.11 \\
\hline$>40$ & $58(52.3)$ & 94 (41.96) & \\
\hline$\leq 40$ & $53(47.75)$ & $130(58.04)$ & \\
\hline Age (means \pm SD) & $41.64 \pm 12.31$ & $39.55 \pm 10.63$ & \\
\hline \multicolumn{3}{|c|}{ Ethno-linguistic group } & $<0.001$ \\
\hline Bantu & $33(29.73)$ & $41(18.30)$ & \\
\hline Semi Bantu & $72(64.86)$ & $182(81.25)$ & \\
\hline Sudano-sao & $6(5.41)$ & $1(0.45)$ & \\
\hline \multicolumn{3}{|l|}{ Menopause status } & $<0.001$ \\
\hline postmenopausal & $34(30.63)$ & $29(12.95)$ & \\
\hline Premenopausal & 77 (69.37) & $195(87.05)$ & \\
\hline \multicolumn{3}{|c|}{ Familial breast cancer } & $<0.001$ \\
\hline Yes & $29(26.13)$ & $16(7.14)$ & \\
\hline No & $82(73.87)$ & $208(92.86)$ & \\
\hline \multicolumn{4}{|l|}{ Histological grade } \\
\hline I, II & $9(8.11)$ & - & \\
\hline III, IV & $102(91.89)$ & - & \\
\hline$P$-value & $<0.0001$ & & \\
\hline \multicolumn{4}{|l|}{ Lymph node } \\
\hline Yes & $71(63.96)$ & - & \\
\hline No & $40(36.04)$ & - & \\
\hline$P$-value & $<0.0001$ & & \\
\hline \multicolumn{4}{|l|}{ Metastasis } \\
\hline Yes & $41(36.94)$ & - & \\
\hline No & $70(63.06)$ & - & \\
\hline$P$-value & $<0.0001$ & & \\
\hline
\end{tabular}

Considering the ethno-linguistic groups, the menopausal status as well as familial BC, significant differences $(p<0.001)$ were observed between patients and controls (Table 1).

From the 111 breast cancer patients, 77 (69.37\%) were premenopausal and $53(47.7 \%)$ were below 40 years. About $91.89 \%(102 / 111)$ all patients were either at stage III or IV while only $8.11 \%(9 / 111)$ were either at stage I or II. Seventy one $(63.96 \%)$ patients had lymph node involvement. Grouping the patients according to lymph node status and tumor size, significant different ( $<<0.0001$ ) were observed (Table 1). About 36.94\% $(41 / 111)$ of patients were found with breast cancer at the metastatic stage (Table 1).

Of the 224 controls, 195 (87\%) were premenopausal and $12.95 \%$ postmenopausal women. About $58.04 \%$ (130/224) of these controls were 40 years or less (Table 1).

With a LD r2 of 1.0 , a disease prevalence of $25 \%$, the disease allele frequencies range from $0.1612-0.205$ for one locus genotyped, and a sampling size of 335 individuals including 111 breast cancer patients and 224 controls, the power of this study was estimated at $95 \%$.

\section{Genotyping results}

The polymorphism at SNP rs 17506395 locus of TP63 was investigated on 111 breast cancer patients and 224 controls belonging to three ethno-linguistic groups. The primers designed in this study successfully amplified all the 335 samples.

\section{Allelic frequencies}

For the entire population, the allelic frequency was $83.9 \%(562 / 670)$ for $\mathrm{T}$ allele and 16.1\% (108/670) for $\mathrm{G}$. In breast cancer patients, the allelic frequencies for $\mathrm{T}$ and $\mathrm{G}$ alleles were $86.9 \%$ (193/222) and 13.1\% (29/222) respectively. In the controls, the allelic frequency was $82.4 \%(369 / 448)$ and $17.6 \%(79 / 448)$ for $\mathrm{T}$ and $\mathrm{G}$ allele, respectively (Table 2). Between patients and controls, no significant difference was observed $(p=0.13)$ in the distribution of the different alleles.

In patients of 40 years or less, the allelic frequencies were respectively $86.79 \%(92 / 106)$ and $13.21 \%(14 / 106)$ for $\mathrm{T}$ and $\mathrm{G}$ alleles. In controls of the same age group, the frequencies of $\mathrm{T}$ and $\mathrm{G}$ alleles were respectively $76.54 \%$ (199/260) and 23.46 (61/260). Between controls and patients of 40 years or less, a significant difference ( $p=0.03 ;$ OR $=0.5,95 \% \mathrm{CI}=0.26-0.94)$ was observed in allelic distribution. These frequencies were $87.07 \%$ $(101 / 116)$ and $12.93 \%(15 / 116)$ respectively for $\mathrm{T}$ and $\mathrm{G}$ alleles in patients above 40 years. For controls of the same group of ages, the frequency of the $\mathrm{T}$ allele was $90.43 \%(170 / 188)$ while that of $G$ was $9.57 \%(18 / 188)$. In women above 40 years, no significant difference $(\mathrm{p}=0$. $313 ; \mathrm{OR}=1.473,95 \% \mathrm{CI}=0.6747-3.215)$ was observed.

In premenopausal patients, the allelic frequency was $87.66 \%(135 / 154)$ for $\mathrm{T}$ allele and $12.34 \%(19 / 154)$ for $\mathrm{G}$. In controls with the same status, the allelic frequencies for $\mathrm{T}$ and $\mathrm{G}$ alleles were respectively $81.03 \%$ (316/390) and $18.97 \%$ (74/390). For postmenopausal patients, the T allele has an allelic frequency of $85.29 \%$ (58/68) while 
DOI:10.31557/APJCP.2020.21.8.2199

The TP63 Gene Polymorphism rs 17506395 is Associated with Early Breast Cancer in Cameroon

Table 2. Allelic Frequencies in Breast Cancer Patients and Controls According to Subpopulations

\begin{tabular}{|c|c|c|c|c|c|c|}
\hline Subpopulation & Alleles & Patients (AF) & Controls (AF) & OR & $95 \% \mathrm{CI}$ & $P$-value \\
\hline \multirow[t]{2}{*}{ Whole population } & $\mathrm{T}$ & $193(86.94)$ & $369(82.40)$ & - & - & 0.129 \\
\hline & G & $29(13.10)$ & 79 (17.60) & 0.70 & $0.44-1.11$ & \\
\hline \multirow[t]{2}{*}{$\leq 40$ years } & $\mathrm{T}$ & 92 (86.79) & $199(76.54)$ & - & - & 0.0311 \\
\hline & G & $14(13.21)$ & $61(23.46)$ & 0.50 & $0.26-0.94$ & \\
\hline \multirow[t]{2}{*}{$>40$ years } & $\mathrm{T}$ & $101(87.07)$ & $170(90.43)$ & - & - & 0.331 \\
\hline & G & $15(12.93)$ & $18(9.57)$ & 1.473 & $0.6747-3.215$ & \\
\hline \multirow[t]{2}{*}{ Premenopausal } & $\mathrm{T}$ & $135(87.66)$ & $316(81.03)$ & - & - & 0.067 \\
\hline & G & $19(12.34)$ & 74 (18.97) & 0.5996 & $0.3471-1.036$ & \\
\hline \multirow[t]{2}{*}{ Postmenopausal } & $\mathrm{T}$ & $58(85.29)$ & $53(91.38)$ & - & - & 0.263 \\
\hline & G & $10(14.71)$ & $5(8.62)$ & 2 & $0.5943-6.73$ & \\
\hline \multirow[t]{2}{*}{ Bantu } & $\mathrm{T}$ & $55(83.33)$ & 65 (79.27) & - & - & 0.538 \\
\hline & G & $11(16.67)$ & $17(20.73)$ & 0.7703 & $0.3359-1.766$ & \\
\hline \multirow[t]{2}{*}{ Semi-Bantu } & $\mathrm{T}$ & 127 (88.19) & $302(82.97)$ & - & - & 0.139 \\
\hline & G & $17(11.81)$ & $62(17.03)$ & 0.6419 & $0.357-1.154$ & \\
\hline \multirow[t]{2}{*}{ Sudano-sao } & $\mathrm{T}$ & $11(91.67)$ & $2(100)$ & - & - & 0.81 \\
\hline & $\mathrm{G}$ & $1(8.33)$ & $0(0.00)$ & 0.6522 & $0.020-21.183$ & \\
\hline
\end{tabular}

$\mathrm{AF}$, Genotypic frequency; OR, odd ratio; $\mathrm{CI}$, confidence interval

that of G allele was $14.71 \%(10 / 68)$ (Table 2). In controls, the allelic frequency was $91.38 \%(53 / 58)$ for $\mathrm{T}$ allele and $8.62 \%(5 / 58)$ for $\mathrm{G}$ (Table 2). No significant difference was observed in the allelic frequencies between patients and controls having pre and postmenopausal status.

The distribution of $\mathrm{T}$ and $\mathrm{G}$ alleles among the different ethno-linguistic groups is summarized in Table 2. In patients, the allelic frequencies for the $\mathrm{T}$ allele were $83.33 \%(55 / 66)$ in the Bantu ethno-linguistic group, $88.19 \%(127 / 144)$ in the semi-Bantu and $91.67 \%$ $(11 / 12)$ in the Sudano-sao group. In controls, these allelic frequencies were $79.27 \%(65 / 82)$ in Bantu ethno-linguistic

Table 3. Genotypic Frequencies in Breast Cancer Patients and Controls According to Subpopulations

\begin{tabular}{|c|c|c|c|c|c|c|c|}
\hline Subpopulation & Genotypes & Patients (GF) & Controls (GF) & OR & $95 \% \mathrm{CI}$ & $P$ value & Cochran-Armitage $\mathrm{p}$-value \\
\hline \multirow[t]{3}{*}{ Whole population } & TT & $82(73.90)$ & $153(68.30)$ & - & - & - & 0.1269 \\
\hline & TG & $29(26.10)$ & $63(28.10)$ & 0.86 & $0.510-1.44$ & 0.562 & \\
\hline & GG & $0(0.00)$ & $8(3.60)$ & 0.11 & $0.006-1.920$ & 0.13 & \\
\hline \multirow{3}{*}{$\leq 40$ years } & $\mathrm{TT}$ & $39(73.58)$ & $77(59.23)$ & - & - & - & 0.03 \\
\hline & TG & $14(26.42)$ & $45(34.62)$ & 0.61 & $0.30-1.25$ & 0.1802 & \\
\hline & GG & $0(0.00)$ & $8(6.15)$ & 0.11 & $0.007-2.052$ & 0.141 & \\
\hline \multirow[t]{3}{*}{$>40$ years } & TT & $43(74.14)$ & $76(80.85)$ & - & - & & 0.33 \\
\hline & TG & $15(25.86)$ & $18(19.15)$ & 1.5 & $0.674-3.21$ & 0.331 & \\
\hline & GG & $0(0.00)$ & $0(0.00)$ & 1.76 & $0.034-90.210$ & 0.78 & \\
\hline \multirow[t]{3}{*}{ Premenopausal } & $\mathrm{TT}$ & $58(75.32)$ & $129(66.15)$ & - & - & - & 0.06 \\
\hline & TG & $19(24.68)$ & $58(29.74)$ & 0.73 & $0.398-1.332$ & 0.304 & \\
\hline & GG & $0(0.00)$ & $8(4.10)$ & 0.13 & $0.074-2.29$ & 0.164 & \\
\hline \multirow[t]{3}{*}{ Postmenopausal } & TT & $24(70.59)$ & $24(82.76)$ & - & - & - & 0.26 \\
\hline & TG & $10(29.41)$ & $5(17.24)$ & 2 & $0.594-6.730$ & 0.262 & \\
\hline & GG & $0(0.00)$ & $0(0.00)$ & 1 & $0.019-52.440$ & 1 & \\
\hline \multirow[t]{3}{*}{ Bantu } & TT & $22(66.67)$ & $27(65.85)$ & - & - & - & 0.54 \\
\hline & TG & $11(33.33)$ & $11(26.83)$ & 0.44 & $0.179-1.06$ & 0.07 & \\
\hline & GG & $0(0.00)$ & $3(7.32)$ & 0.17 & $0.0086-3.560$ & 0.25 & \\
\hline \multirow[t]{3}{*}{ Semi-Bantu } & $\mathrm{TT}$ & $55(76.39)$ & $125(68.68)$ & - & - & - & 0.14 \\
\hline & TG & $17(23.61)$ & $52(28.57)$ & 0.74 & $0.395-1.399$ & 0.3575 & \\
\hline & GG & $0(0.00)$ & $5(2.75)$ & 0.2 & $0.011-3.782$ & 0.287 & \\
\hline \multirow[t]{3}{*}{ Sudano-sao } & $\mathrm{TT}$ & $5(83.33)$ & $1(100)$ & - & - & - & 0.66 \\
\hline & TG & $1(16.67)$ & $0(0.00)$ & 0.818 & $0.021-32.270$ & 0.915 & \\
\hline & GG & $0(0.00)$ & $0(0.00)$ & 0.3 & $0.0036-20.420$ & 0.555 & \\
\hline
\end{tabular}

GF, Genotypic frequency; OR, odd ratio; CI, confidence interval 
Table 4. Cochran-Mantel-Haentel (CMH) Association Analysis Results within each Subpopulation

\begin{tabular}{lccccccc}
\hline Strata & alleles & MAF & $P$-value & CHISQ & aP-value & ${ }^{a}$ CHISQ & OR (95\%CI) \\
\hline Age group & $* \mathrm{~T}$ & 0.1612 & 0.2261 & 1.465 & 0.00116 & 10.55 & $0.7507(0.471-1.194)$ \\
& $* * \mathrm{G}$ & & & & & & \\
Menopausal status & $* \mathrm{~T}$ & 0.1612 & 0.2133 & 1.549 & 0.249 & 1.32 & $0.74(0.459-1.185)$ \\
& $* * \mathrm{G}$ & & & & & & \\
Ethno-linguistic group & $* \mathrm{~T}$ & 0.1612 & 0.1256 & 2.346 & 0.371 & 1.98 & $0.6912(0.4312-1.108)$ \\
& $* * \mathrm{G}$ & & & & & & \\
\hline
\end{tabular}

$P$-value, Nominal CMH P asymptotic probability value; **, minor allele; *major allele, CHISQ: Chi-square probability value; OR: odds ratio; MAF, Minor allele frequency; ${ }^{\text {a }}$ Cochran-Mantel-Haenszel for homogeneity of association across clusters (using the cmh2 test in plink

group, $82.97 \%(302 / 364)$ in the semi-Bantu and $100 \%$ $(2 / 2)$ in the Sudano-sao group. For the G allele, the allelic frequencies in patients were $16.67 \%(11 / 66)$ in the Bantu, $11.81 \%(17 / 144)$ in the semi-Bantu and $8.33 \%(1 / 12)$ in the Sudano-sao. For the same ethno-linguistic groups, similar trends were observed for the allelic frequencies in controls: $20.73 \%(17 / 82)$ for the allelic frequency in the Bantu ethno-linguistic group, 17.03\% (62/364) for the-Bantu and none for the Sudano-sao (Table 2). However, not all of these distributions are statistically significant (Table 2).

\section{Genotypic frequencies}

For the entire population, the genotypic frequencies were $24.5 \%$ (92/335) for TG genotype (heterozygote), $2.4 \%(8 / 335)$ for GG genotype (homozygote mutant) and $67.2 \%(235 / 335)$ for TT genotype (homozygote wild type) (Table 3 ). In patients, $73.90 \%$ (82/111) were of the TT genotype and $26.10 \%(29 / 111)$ TG genotype (Table 3). In the controls, 68.30\% (153/224) and 3.60\% $(8 / 224)$ of women were homozygote wild type and mutant respectively while $28.10 \%(63 / 224)$ were heterozygotes (Table 3). In the entire population, no significant difference was observed ( $\mathrm{p}=0.13$ and 0.56 for $\mathrm{GG}$ and TG respectively) in the genotypic distribution between

Table 5. Relationship between rs17506395 and Known Clinicopathological Variables

\begin{tabular}{lcccc}
\hline $\begin{array}{l}\text { Clinicopathological } \\
\text { variables }\end{array}$ & $\begin{array}{c}\text { Number } \\
(\mathrm{n}=111)\end{array}$ & \multicolumn{2}{c}{ Genotype (\%) } & $P$-value \\
\hline Age (years) & & & TT & \\
$\quad \leq 40$ & 53 & $14(26.42)$ & $39(73.58)$ & \\
$>40$ & 58 & $15(25.86)$ & $43(74.14)$ & \\
Site of Breast & & & & 0.947 \\
Left & 53 & $15(28.30)$ & $38(71.70)$ & \\
Right & 54 & $13(24.07)$ & $41(75.93)$ & \\
Bilateral & 4 & $1(25)$ & $3(75)$ & \\
Tumor stage & & & & 0.192 \\
I, II & 9 & $4(44.44)$ & $5(55.60)$ & \\
III, IV & 102 & $25(24.51)$ & $77(75.49)$ & \\
Lymph node & & & & 0.27 \\
Yes & 71 & $21(29.58)$ & $50(71.42)$ & \\
No & 40 & $8(20)$ & $32(80)$ & \\
Metastasis & & & & \\
Yes & 41 & $13(31.71)$ & $28(68.29)$ & \\
No & 70 & $16(22.86)$ & $54(77.14)$ & \\
\hline
\end{tabular}

patients and controls (Table 3).

The GG genotype was present only in controls of 40 years or less (Table 3). About 73.58\% (39/53) of patients of 40 years or less were homozygote wild type while $26.42 \%(14 / 53)$ were heterozygote. In controls of the same age, $34.62 \%(45 / 130)$ were heterozygote while $59.23 \%(77 / 130)$ and $6.15 \%(8 / 130)$ were homozygote wild type and mutant respectively. Between controls and patients of 40 years or less, a significant difference $(\mathrm{p}=$ 0.03 ) was observed in their genotypic frequencies (Table 3 ). In patients above 40 years, the genotypic frequencies were $74.14 \%(43 / 58)$ for the homozygote wild type and $25.86 \%(15 / 58)$ for the heterozygote. In controls of the same age, $80.85 \%(76 / 94)$ and $19.15 \%$ (18/94) were respectively homozygote wild type and heterozygote. No participant above 40 years (either patients or controls) carried the homozygote mutant genotype (Table 3 ). No significant difference ( $p=0.33$ ) was found for the genotypic frequencies between patients and controls who were above 40 years (Table 3 ).

From the 77 premenopausal patients, the genotypic frequencies were $75.32 \%(58 / 77)$ for TT genotype and $24.68 \%$ (19/77) for TG genotype. None of these women was found with GG genotype. In 195 controls of the same menopausal status, the genotypic frequencies were $66.15 \%$ (129/195) for TT genotype, $29.74 \%$ (58/195) for TG genotype and $4.10 \%(8 / 195)$ for GG genotype. In postmenopausal patients, the genotypic frequencies were $70.59 \%$ (24/34) for the TT genotype and $29.41 \%$ $(10 / 34)$ for TG genotype. For controls having the same menopausal status, the genotypic frequencies were $82.76 \%$ (24/29) for TT genotype and 17.24\% (5/29) for TG genotype (Table 3 ). No postmenopausal woman was found with GG genotype either in patient or in controls (Table 3). Comparing the genotypic frequencies between patients and controls in pre and postmenopausal women, no significant difference was observed (Table 3 ).

The GG genotype was only found in controls of the Bantu and semi-Bantu ethno-linguistic groups with respective genotypic frequencies of $7.32 \%(3 / 41)$ and $2.75 \%(5 / 182)$. In contrast, other genotypes were present in all ethno-linguistic groups (Table 3). In fact, for the patients of the semi-bantu group, the genotypic frequencies were $76.39 \%(55 / 72)$ and $23.61 \%(17 / 72)$ for TT and TG genotypes respectively. In controls of this group, we found $68.68 \%(125 / 182)$ and $28.57 \%(52 / 182)$ for TT and TG genotypes respectively.

Among the Bantu group, the TT and TG genotypes

. 
have respective genotypic frequencies of $66.67 \%(22 / 33)$ and $33.33 \%(11 / 33)$ for patients; and $65.85 \%(27 / 41)$ and $26.83 \%(11 / 41)$ for controls. The genotypic frequencies for TT and TG genotypes were respectively $83.33 \%(5 / 6)$ and $16.67(1 / 6)$ for patients in the Sudano-sao group. The only one control of this group has TT genotype. Whatever, the ethno-linguistic group, no significant difference was observed in the genotypic frequencies between patients and controls..

Association between polymorphism at SNP rs 17506395 and the risk of developing breast cancer in the whole population

The overall population was in Hardy-Weinberg equilibrium $(p=1)$. The Cochran-Armitage trend test performed using the genotypic frequencies of the overall study population revealed no significant association ( $\mathrm{p}=$ 0.1269 ) between the polymorphism at SNP rs 17506395 and the risk of developing breast cancer in our study population (Table 4). These results are in agreement with those of the allelic frequencies reporting no significant difference between patients and controls $(\mathrm{p}=0.1287, \mathrm{OR}=$ $0.7,95 \% \mathrm{CI}=0.44-1.11$ ) (Table 3 ). Whatever the genotype considered, no significant difference (genotype TG: $\mathrm{p}=$ $0.562, \mathrm{OR}=0.86,95 \% \mathrm{CI}=0.510-1.44$; genotype $\mathrm{GG}$ : $\mathrm{p}=0.130, \mathrm{OR}=0.11,95 \% \mathrm{CI}=0.006-1.920)$ was found between patients and controls (Table 4).

To see if these results could be bias by the heterogeneity of the study population, additional analyses were carried out on the populations stratified on the basic of their menopausal status, ethno-linguistic groups as well as age groups.

Association between polymorphism at SNP rs17506395 and the risk of developing breast cancer in women of different Subpopulations

Data from the Cochran-Mantel-Haenszel (CMH) and CMH2 tests reported in Table 4 includes all 111 patients and 222 controls. The null hypothesis of the $\mathrm{CMH}$ test is that the allele frequencies are the same in cases and controls and do not differ between populations. Whatever the subpopulation considered in the association studies performed with the $\mathrm{CMH}$ test, the minor allele $\mathrm{G}$ of rs 17506395 was not associated $(p>0.1)$ with breast cancer development (Table 4). However, with the $\mathrm{CMH} 2$ test for which the null hypothesis is described by the same allele frequencies in each population, a significant difference $(\mathrm{P}$ $=0.00116, X^{2}=10.55$ ) was observed in allele frequencies between the age groups. The odds ratio at $95 \%$ confidence intervals estimated using the unconditional logistic regression models are reported in Table 2. No significant association was observed for the subpopulations subdivided on the basis of their menopausal status and Ethno-linguistic groups (Table 4).

Association between polymorphism at SNP rs 17506395 of TP63 and the risk of developing breast cancer in women of different age groups

The Cochran-Armitage trend test found an association (Cochran-Armitage $\mathrm{P}$ value $=0.03$ ) between genotype combinations ([TT $+\mathrm{TG}]$ versus $[\mathrm{GG}])$ and the risk of breast cancer development in women of 40 years and less
(Table 3). The GG genotype appears to reduce the risk of breast cancer development among women 40 years or less (Table 3). The unconditional logistic regression analysis revealed that women of 40 years or less and who carry the $\mathrm{G}$ allele had a significantly decreased risk ( $\mathrm{p}=0.0311, \mathrm{OR}=0.5,95 \% \mathrm{CI}=0.26-0.94)$ of developing breast cancer compared to those carrying T allele (Table 2). This result indicates that the $\mathrm{G}$ allele has a protective effect on the development of breast cancer in this group of women. For women above 40 years, no association $($ Cochran-Armitage $P$ value $=0.33)$ was observed between the number of variant alleles and the risk of developing breast cancer (Table 3 ).

Association between polymorphism at rs17506395 and the risk of developing breast cancer in women of different menopausal status

For this association study, the participants were subdivided into 272 premenopausal women (77 breast cancer patients and 195 controls) and 63 postmenopausal women (34 patients and 29 controls). Using the unconditional logistic regression analysis, no association $(\mathrm{p}=0.067, \mathrm{OR}=0.5996$ ? 95\%CI 0.3471-1.036) was observed for the allelic frequencies in premenopausal women (Table 3). The Cochran-Armitage trend test and the unconditional logistic regression models revealed also no association between the number of variant alleles and the risk of developing breast cancer among women of this subpopulation (Tables 3 and 4). In the postmenopausal women, no association was found when different tests were applied on the allelic frequencies $(p=0.263, \mathrm{OR}=2$, $95 \mathrm{CI} \%=0.5943-6.73$ ) or the genotypic frequencies (for $\mathrm{TG}, \mathrm{p}=0.262, \mathrm{OR}=2,95 \mathrm{CI} \%=0.594-6.730$ and for $\mathrm{GG}$, $\mathrm{p}=1, \mathrm{OR}=1,95 \% \mathrm{CI}=0.019-52.440)$. These results were confirmed by the Cochran-Armitage trend test (Table 3 ).

Association between polymorphism at rs 17506395 and the risk of developing breast cancer in different to ethnolinguistic groups

Between patients and controls, and within the different ethno-linguistic groups, no significant difference was found in the allelic frequencies when the unconditional logistic regression model was used (Table 2). The Cochran-Armitage trend test performed between patients and controls belonging to different ethno-linguistic groups also revealed no association (Cochran-Armitage $p>0.1)$ between the number of variant alleles and the risk of developing breast cancer in these subpopulations (Table 3).

Additional association studies with the tests used above revealed no significant association between polymorphism at SNP rs 17506395 of TP63 gene and the risk of developing breast cancer in women presenting different clinico-pathological features of the disease (Table 5).

\section{Discussion}

The evaluation of genetic variants associated with the risk of $\mathrm{BC}$ development has led to a better understanding of the relationship between genomics 
and cancer development. Such relationships have been fundamentally based on SNPs, which generally carry the most common pattern of genetic variation in the human genome (Chang-Sheng et al., 2018). Zhang et al., (2014) have shown an association between polymorphism at SNP rs 17506395 of the TP63 gene and the breast cancer in Asian population. Although the definition of young women with breast cancer is still controversial with different authors defining different ages as young and varying from 30 to 45 years (Bollet et al., 2007; Kruger and Apffelstaedt, 2009), all women of 40 years and below were considered in our study as young, otherwise they were of old age. Our classification is in agreement with age stratifications that have recently been used in several studies (Bharat et al.,, 2009; Dia et al., 2017; Johnson et al., 2015; Karihtala et al., 2010; Lian et al., 2017).

Our results showing that the $\mathrm{T}$ allele seems to be widely spread in Cameroonian Women are in agreement with those obtained from the 1000 Genomes project where the $\mathrm{T}$ allele represents $89 \%$ against $11 \%$ for $\mathrm{G}$ allele (Hunt et al., 2018). However, the present study shows a significant difference $(p=0.03)$ in the allelic frequencies of $\mathrm{T}$ allele between patients and controls for women of age 40 years and or less. On the other hand, no significant difference was observed between controls and patients of above 40 years as well as in the entire population or participants grouped according to their ethno-linguistic groups or menopausal status. The presence of $\mathrm{T}$ allele seems to have an impact on breast cancer outcome in women of 40 years and less. This hypothesis is in line with observation of Zhang et al. (2014) reporting high frequency of $\mathrm{T}$ allele in breast cancer patients. In Asian women for instance, Zhang et al., (2014) observed 70.33\% of $\mathrm{T}$ allele in controls against $78.69 \%$ in patients. In our study, such difference was observed only in participants of 40 years and less $(86.79 \%$ for patients versus $76.54 \%$ for controls). From the differences in the allelic frequencies, it was inferred that the single present of $\mathrm{T}$ allele seems sufficient to increase the risk of developing breast cancer in Asian women. The presence of T allele seems therefore to be associated with the risk of developing breast cancer in women of 40 years and less. Although the mechanism associating the presence of T allele at SNP rs 17506395 with breast cancer is not yet understood, this allele seems to be able to alter the regulator power of TP63 gene, which could contribute to breast cancer development (Zhang et al., 2014). It was suggested that the T allele, which is mostly observed in breast cancer patients, may enhance the expression of TP63 gene. If we assume that, it is likely that the high frequency of $\mathrm{T}$ allele among young patients may promote high expression of TP63, which in tune drive the aggressiveness of basal-like breast cancer. Previous studies highlight that the total percentage of p63-positive cells was related to a marked nuclear pleomorphism and that the intensity of $p 63$ staining was associated with a syncytial growth pattern in triple negative breast cancer (Thike et al., 2010). Moreover, higher expression of p63 was reported in the cytoplasm cells of basal-like subtype breast cancer compared to non-basal-like of Indonesian women (Kamarlis et al., 2018). Results obtained in young Cameroonian patients highlighting the high allelic frequency for $\mathrm{T}$ allele could be linked to aggressiveness of breast cancer in the young black women because breast cancer in women of below 40 years is more aggressive with a worse clinical outcome compared to older group (Anders et al., 2010; Carvalho et al., 2010; Karihtala et al., 2010). The exact mechanism underlying the function of this polymorphism has not been unveiled and functional studies are required in order to understand the biological function related to the polymorphism observed at SNP of rs 17506395 of TP63 gene.

In our study, the $G$ allele seems to be predominant in the young population because its allelic frequency was $23.46 \%$ and $13.21 \%$ in controls and patients of 40 years and less against $9.57 \%$ and $12.93 \%$ in those above 40 years. These results are in agreement with those obtained in Asian women where Zhang et al., (2014) reported 50.4\% of young women (below 48 years) carrying $\mathrm{G}$ allele against $17.3 \%$ in patients above 48 years although the grouping by age was different. In the present study, the allelic frequency for $\mathrm{G}$ allele was significantly high in controls than patients of 40 years and less. However, no significant difference was observed for the allelic frequencies between controls and patients when all participants or the ethno-linguistic groups or the menopausal status were taken into consideration. These results suggest the implication of $\mathrm{G}$ allele in the breast cancer outcome in participants of 40 years and less. For this allele, an odds ratio of 0.5 and a significant $p$ value of 0.03 suggest that the presence of $\mathrm{G}$ allele could reduce the risk of developing breast cancer in the young Cameroonian women. This allele may have a protecting effect against breast cancer in Cameroonian women of 40 years and less; this effect has been reported elsewhere by Zhang et al., (2014).

The Cochran-Armitage test for trend revealed an association between the combination of TT and TG genotypes with the risk of developing breast cancer in of women of 40 years and less. These results are in agreement with those of Zhang et al., (2014). These authors reported the TT genotype to be associated with unfavorable survival of breast cancer; suggesting this genotype as potential biomarker for adverse prognosis of breast cancer in Asian women. According to results of Cochran-Armitage trend test on the group of women of 40 years and less, the GG genotype seems to be associated $(\mathrm{p}=0.03)$ with a decreasing risk of developing breast cancer. These results are in agreement with those obtained by Zhang et al., (2014) who found that breast tumors with TT genotype exhibited higher level of TP63 $m R N A$ compared with other genotypes in breast cancer tissues, indicating that $r s 17506395$ may be a functional single nucleotide polymorphism in breast cancer. The presence of TT genotype was statistically correlated with increased risk for breast cancer, compared with genotypes containing the $\mathrm{G}$ allele (GG and GT). If the presence of $\mathrm{T}$ allele may enhance the expression of the TP63 gene, such phenomenon may subsequently drive tumorigenesis than the GG and GT genotypes could do (Zhang et al., 2014). Moreover, an increase in the expression level of TP63 gene is generally observed in less differentiated or more aggressive tumors, which would indicate the correlation between an increase in p63 expression and 
a poor prognosis (Hsiao et al., 2010). Therefore, the association of this functional variant $r s 17506395$ of the TP63 gene in young Cameroonian women would partially justify the aggressiveness of cancer among young black women in sub-Saharan Africa.

Our study failed to find significant association between polymorphism at rs 15706395 of TP63 gene and risk of developing breast cancer in different ethno-linguistic groups. These results suggest that the $r s 15706395$ variant of the TP63 gene could exert its effect regardless of ethno-linguistic groups. Although the power of our study is $95 \%$, it is important to point out that the low sample size of the sudano-soa ethno-linguistic group might have an impact on the outcome of this study. This low sample size of women belonging to the Sudano-sao group could partially be explained by some cultural behavior and believes. Indeed, women belonging to this ethno-linguistic group are generally reluctant to participate in Breast and cervical cancer screening programs (Banning et al., 2009; Padela et al., 2016). Additional studies need to be conducted in larger sample sizes to validate these findings.

In conclusion, results of this study revealed an association between polymorphism at SNP rs 15706395 of TP63 gene and the risk of developing breast cancer among Cameroonian women of 40 years and less. The GG genotype seems to reduce the risk of developing breast cancer in young Cameroonian women. Further studies using larger sample sizes are needed to provide more conclusive evidences. Such studies could enable to confirm the potential of this SNP as biomarker for breast cancer prognostic.

\section{Acknowledgements}

This article is part of the $\mathrm{PhD}$ thesis conducted in the Faculty of Science at the University of Dschang, in the Parasitology and Molecular Entomology sub-unit of the Department of Biochemistry. We would like to thank the Director of General Hospital of Douala and the Director of the "Cancer Center" of clinic St. Joseph of Fouda of Yaounde for collecting the clinical samples. We are also grateful for the participants collaboration received from the participating hospitals and their staff.

\section{Ethical issue}

All participants voluntarily signed written informed consent forms prior to their inclusion into the study. Each blood sample was taken by a nurse to avoid possible inconvenience. All participant samples data were anonymised. These achievements were made after ethical approval approved by the Ethics Review and Consultancy Committee (ERCC) of the Cameroon Bioethics Initiative (CAMBIN) under the reference number CBI/395/ERCC/ CAMBIN and Protocol number 1086 in accordance of the Declaration of Helsinki.

\section{Author contributions}

Conceptualization: Gustave Simo, Smiths Lueong Formal analysis: Arnol A. Zébazé Tiofack, Elvis A. Ofon

Methodology: Arnol A. Zébazé Tiofack, Smiths
Lueong, Gustave Simo.

Identification of patients and controls: Ester Dina bell, Chancelin M. Kamla, Sidonie N. Ananga, Tchamfong Roger, Theophile N. Nana, Charlotte T. Nguefack, Adamou Fewou.

PhD Thesis supervisions: Samuel Takongmo, Gustave Simo.

Writing - original draft: Arnol A. Zébazé Tiofack,

Gustave Simo, Smiths Lueong

All authors read and approved the final manuscript.

Competing interests

All authors have declared no competing interests.

\section{References}

Abdulrahman GO, Rahman GA (2012). Epidemiology of breast cancer in Europe and Africa. J Cancer Epidemiol, 2012, 915610.

Anders C, Johnson R, Litton J, Phillips M, Bleyer A (2009). Breast cancer before age 40 years. Semin Oncol, 36, 237-49.

Atangana PJC, Tchenté NC, Kabeyene OAC, et al (2017). Aspects Immunohistochimiques des Cancers du Sein à Douala et Yaoundé. Health Sci Dis, 18, 14-20.

Banning M, Hafeez H, Faisal S, Hassan M, Zafar A (2009). The impact of culture and sociological and psychological issues on Muslim patients with breast cancer in Pakistan. Cancer Nurs, 32, 317-24.

Barbareschi M, Pecciarini L, Cangi MG, et al (2001). P63, a P53 homologue, is a selective nuclear marker of myoepithelial cells of the human Breast. Am J Surg Pathol, 25, 1054-60.

Bharat A, Aft RL, Gao F, Margenthaler JA (2009). Patient and tumor characteristics associated with increased mortality in young women ( $\leq 40$ years ) with breast cancer. $J$ Surg Oncol, 100, 248-51.

Bleyer A, Barr R, Hayes-lattin B, et al (2008). The distinctive biology of cancer in adolescents and young adults. Nat Rev Cancer, 8, 288-98.

Bollet MA, Sigal-Zafrani B, Mazeau V, et al (2007). Age remains the first prognostic factor for loco-regional breast cancer recurrence in young $(<40$ years) women treated with breast conserving surgery first. Radiother Oncol, 82, 272-80.

Bray F, Ferlay J, Soerjomataram I, et al (2018). Global Cancer Statistics 2018: GLOBOCAN Estimates of Incidence and Mortality Worldwide for 36 Cancers in 185 Countries. $C A$ Cancer J Clin, 68, 394-424.

Carvalho FM, Bacchi LM, Santos PPC, Bacchi CE (2010). Triple-negative breast carcinomas are a heterogeneous entity that differs between young and old patients. Clinics, 65, 1033-36.

Chang-Sheng C, Kitamura E, Johnson J, Bollag R, Hawthorn L (2018). Genomics analysis of racial differences in triple negative breast cancer. Genomics, 111, 1529-42.

Dia JM, Touré M, Yao I, et al (2017). Breast cancers in young woman under 40 years in sub-Saharan Africa: Experience of the Gynecology Department of the University and Hospital Center of Treichville (Abidjan - Cote d 'Ivoire). J Cancer Ther, 8, 714-25.

Deeks JJ, Higgins JPT (2010). Statistical algorithms in Review Manager 5. Retrieved from https://training.cochrane.org/ handbook/statistical-methods-revman5.

Eng A, McCormack V, dos-Santos-Silva I (2014). Receptordefined subtypes of breast cancer in indigenous populations in Africa: a systematic review and meta-analysis. PLoS Med, 11, e1001720.

Essiben F, Foumane P, Meka ENU, et al (2016). Risk factors Asian Pacific Journal of Cancer Prevention, Vol 21 
for breast cancer: A case-control study of 315 women followed in the gynecology and oncology departments of two University Teaching Hospitals in Yaounde, Cameroon. Open J Obstet Gynecol, 6, 676-88.

Feng Z, Zhang C, Kang HJ, et al (2011). Regulation of female reproduction by $\mathrm{p} 53$ and its family members. FASEB J, 25, 2245-55.

Ferlay J, Soerjomataram I, Dikshit R, et al (2015) Cancer incidence and mortality worldwide: sources, methods and major patterns in GLOBOCAN. Int J Cancer, 136, 359-86.

Ferlay J, Steliarova-Foucher E, Lortet-Tieulent J, et al (2013). Reprint of: Cancer incidence and mortality patterns in Europe: Estimates for 40 countries in 2012. Eur J Cancer, 49, 1374-403.

Galukande M, Wabinga H, Mirembe F, Karamagi C, Asea A (2014). Molecular breast cancer subtypes prevalence in an indigenous Sub Saharan African population. Pan Afr Med $J, \mathbf{1 7}, 249$.

Gnerlich JL, Deshpande A, Jeffe DB, et al (2009). Elevated breast cancer mortality in women younger than age 40 years compared with older women is attributed to poorer survival in early-stage disease. J Am Coll Surg, 208, 341-7.

Guan X, Zhang N, Yin Y, et al (2012). Polymorphisms in the p63 and p73 genes are associated with ovarian cancer risk and clinicopathological variables. J Exp Clin Cancer Res, 31, 1-8.

HsiaoY, Su YA, Tsai H, et al (2010). Increased invasiveness and aggressiveness in breast epithelia with cytoplasmic p63 expression. Int J Biol Sci, 6, 428-42.

Hunt SE, McLaren W, Gil L, et al (2018). Ensembl variation resources. Database, 2018, 1-12.

Jedy-Agba E, McCormack V, Adebamowo C, dos-Santos-Silva I (2016). Stage at diagnosis of breast cancer in sub-Saharan Africa: a systematic review and meta-analysis. Lancet Glob Health, 4, 923-35.

Johnson RH, Hu P, Fan C, Anders CK (2015). Gene expression in "young adult type" breast cancer: a retrospective analysis. Oncotarget, 6, 13688-702.

Kamarlis RK, Lubis MN, Hernowo BS, Kar AS (2018). Immunoexpression of P63 and SOX2 in triple-negative breast cancers, Indonesia. F1000Res, 6, 1780.

Karihtala P, Winqvist R, Bloigu R, Jukkola-Vuorinen A (2010). Long-term observational follow-up study of breast cancer diagnosed in women $\leq 40$ years old. Breast $J, 19,456-61$.

Kasiulevicius V, Sapoka V, Filipaviciute R (2006). Sample size calculation in epidemiological studies. Gerontologija, 7, 225-31.

Kemfang NJD, Kasia JM, Yomi J, et al (2015). Breast cancer survival in Cameroon: Analysof a Cohort of 404 Patients at the Yaoundé General Hospital. Adv Breast Cancer Res, 4, 44-52.

Kemfang NJD, Yomi J, Kasia JM, et al (2011). Breast cancer profile in a group of patients followed up at the radiation therapy unit of the Yaounde General Hospital, Cameroon. Obstet Gynecol Int, 2011, 1-5.

Kruger W, Apffelstaedt J (2009). Young breast cancer patients in the developing world: incidence, choice of surgical treatment and genetic factors. South Afr J Gynaecol Oncol, 1, 29-30.

Lian W, Fu F, Lin Y, et al (2017). The impact of young age for prognosis by subtype in women with early breast cancer. Sci Rep, 7, 11625.

Ly M, Antoine M, Demblélé AK, et al (2012). High incidence of triple-negative tumors in sub-saharan africa: A prospective study of breast cancer characteristics and risk factors in malian women seen in a bamako university hospital. Oncology, 83, 257-63.

Mavaddat N, Antoniou AC, Easton DF, Garcia-Closas M
(2010). Genetic susceptibility to breast cancer. Mol Oncol, 4, 174-91.

Menashe I, Rosenberg PS, Chen BE (2008). PGA: power calculator for case-control genetic association analyses. BMC Genet, 9, 36.

Karim MSA, Ghalib AHH, Mohammed SA, Fattah FHR (2015). The incidence, age at diagnosis of breast cancer in the Iraqi Kurdish population and comparison to some other countries of Middle-East and West. Int J Surg, 13, 71-5.

Ofon E, Noyes H, Mulindwa J, et al (2017). A polymorphism in the haptoglobin, haptoglobin related protein locus is associated with risk of human sleeping sickness within Cameroonian populations. PLoS Negl Trop Dis, 11, e0005979.

Ouedraogo MLN, Zongo N, Zida M, et al (2018). Breast cancer in women under 40 years old at Yalgado Ouedraogo University Hospital ( Burkina Faso ). JSM Surg Oncol Res, 3, 1022.

Padela AI, Vu M, Muhammad H, et al (2016). Religious beliefs and mammography intention: findings from a qualitative study of a diverse group of American Muslim women. Psychooncology, 25, 1175-82.

Pagano M, Gauvreau K (2000). Principles of Biostatistics, 2nd ed. Duxbury, Pacific Grove.

Purcell S, Neale B, Todd-Brown K, et al (2007). PLINK: a toolset for whole-genome association and population-based linkage analysis. Am J Hum Genet, 81, 559-75.

Sando Z, Fouogue JT, Fouelifack FY, et al (2014). Profil des cancers gynécologiques et mammaires à Yaoundé - Cameroun. Pan Afr Med J, 17, 28.

Sawe RT, Kerper M, Badve S, et al (2016). Aggressive breast cancer in western Kenya has early onset, high proliferation, and immune cell infiltration. BMC Cancer, 16, 204.

ThikeAA, Cheok PY, Jara-Lazaro AR, et al (2010). Triple-negative breast cancer: Clinicopathological characteristics and relationship with basal-like breast cancer. Mod Pathol, 23, 123-33.

Tichy JR, Lim E, Anders CK (2013). Breast cancer in adolescents and young adults: A review with a focus on biology. Pan Afr Med J, 11, 1060-9.

Vanderpuye V, Grover S, Hammad N, et al (2017). An update on the management of breast cancer in Africa. Infect Agent Cancer, 12, 13.

Wonkam A, Kenfack MA, Muna WFT, Ouwe-missioukem-boyer O (2011). Ethics of human genetic studies in sub-saharan africa: the case of Cameroon through a bibliometric analysis. Dev World Bioeth, 11, 120-7.

Ye J, Coulouris G, Zaretskaya I, et al (2012). Primer-BLAST: A tool to design target-specific primers for polymerase chain reaction. BMC Bioinformatics, 13, 134.

Zhang N, Huo Q, Wang X, et al (2014). A genetic variant in p63 (rs17506395) is associated with breast cancer susceptibility and prognosis. Gene, $\mathbf{5 3 5}, 170-6$.

Zhao JH (2007). gap: Genetic Analysis Package. J Stat S, 23, $1-18$.

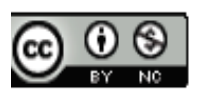

This work is licensed under a Creative Commons AttributionNon Commercial 4.0 International License. 